\title{
Ict As A Change Agent For Socialization And Social Engineering
}

\author{
Engr.Wali Samuel, Samuel Godwin Ajumo, Else Chindinma Anderson and \\ Steve Worgu \\ Department of Computer Engineering Technology, Port Harcourt Polytechnic Rumuola, Rivers state, Nigeria.
}

\begin{abstract}
The future communication has been predicted to depend to a great degree on electronic modes; academics businessmen and professionals in various fields, purpose, various uses of ICT facilities and new media generally these and many decisions will be made based only on available data concerning these media. It is recorded that at least four million seven hundred and fourteen Nigerians are on face-book and other social media with a good number of them being young (face book statistics 2012). However, there is no comprehensive knowledge of these activities as well as how its form of media and its usage by Nigerian youths. The study specifically focuses on the usage habit of young Nigerians and how ICT has affected their communication and socialization habits.
\end{abstract}

Keywords: ICT, Change, Socialization and Social Engineering.

\section{Introduction}

As the ICT has become ubiquitous, faster and increasingly accessible to non-technical communities, social networking and collaborative services have grown rapidly enabling people to communicate and share interest in many more ways, sites life face book, twitter linked in youtube, flicker, second life delicious blogs wiki's and many more let people of all ages rapidly share their interest of the movement without others every where. But face book seems to be the leading areas of were people communicate and share their opinions. What's a change! "Nothing is permanent, but change" (As Heraditus in the $4^{\text {th }}$ century BC). Internet can be seen as the international networks of inter-connection of computer networks, the main purpose for the institution of internet are quest for information i.e. browsing, electronic mail, new groups fill transfer and access and use of other computer.

Socialization can be seen as a process by which a child adapts a behaviour to be an effective member of the society, which can only be achieved through learning or education. Education in the other hand; in the words of Owo, C. (2000) is the entire process of human learning by which knowledge is acquired or imparted, faculties trained and skills developed. Education is neither confined to classrooms teachers and textbooks nor does it ends when formal schooling is completed. It is a part of complex process of socialization which transforms a new born child into a social being capable of participating effectively in the society. Education continues as long as a person learns to adapt to new circumstances, and play new roles. Education as a vital institution of the society performs the following functions; preservation of culture, economic function, career preparation, social selection, political function and innovative function.

Boyd (2010) says communication is a basic human and for that reason, man has always found the means of meeting these need. The media which is an umbrella term for various means of communication, has become an internal part of human life around the world. The earliest forms of personal media, speech and gestures, had the benefit of being easy to use and did not necessarily need complex technology. The weaknesses of not being able to communicate to large audiences led to the development of ICT such as writing.

Today technology has made more universal ability to produce media, printing, radio and television are some examples of mass media in that they are intended to reach at audience. Also it has made wave and brought change in social engineering which has to do with looking out for more reliable techniques of bettering the lives of people for instance villagization is part of social media which is concentrated on considering other economic ways other then farming that can better the lives of people such as lives stock rearing or the mixture of the two. To this effect the inability of the society to survive without proper incentive or communication gadgets now gave rise to the emergence of ICT as a change agent for socialization and social engineering.

\section{Brief on Ict}

In November 1922 precisely, Delphi was the first national commercial online service to offer internet access to its subscribers, it opened up an email connection in July 1992 and full internet service.

All pretenses of limitations on commercial networks AOL, prodigy and compu-service came online, since commercial usage was so wise spread by this time and educational institutions had been paying there own way for some time, the loss of NSF findings had no appreciable effection costs. Today NSF findings has moved beyond supporting the backbone and higher educational institutions to building the k-12 and public library 
success on the one hand, and the research on the massive high volume connections on the other. In June 1998 Microsoft's release windows 98 which came with the Microsoft Browser will integrated into the Desktop shows bill gates determination to capitalize on the enormous growth of the internet Microsoft success over the past few years ahs brought count challenges to their dominance.

During this period of enormous growth, business entering the ICT arena scrumbled to find economic models that work free service supported by advertising shifted some of the direct costs away from one customer temporarily service such as Delphi offered free web pages, chatrooms and message boards for community building. Online sales have grown rapidly for such products as books and music CDS and computers but the profits margins are slim when price comparisons are so easy and public trust in online security is still shaky. Business models that have worked well are portal sites that try to provide everything for every body and live auctions. A current turned with major implications for the future is the growth of high speed connections. 56k modems and the providers who supported them spread widely for a while but this is the low and now, 56k is not fast enough to carry multimedia such as sound video except in low quality. But new technologies many times faster, such as cable modems and digital subscribers line (DSL) are predominantly now.

\section{Villagization as Social Engineering}

States, more or less invariably, prefer settled forms be it farming, livestock rearing, or a mix of the two - rather than transient forms of agriculture. The Ethiopian state is no exception. Despite difference sin political philosophies and perspectives, the imperial, military, post - 1991 governments have been arguing against (agro) pastoralism and shifting cultivation, and have pursued policies encouraging the population subsisting through these livelihoods to settle. However, there were no meaningful large-scale efforts, let alone successors before the second decade of the $21^{\text {st }}$ century.

Report on the villagization program usually focuses on how it is being implemented and its relation with the ongoing land deals. As is the case in most social and political processes, the means of do not necessarily determine the end. This should not be construed to mean that actions should simply plough though their plans without due consideration to the rights of local people, along with ethical and moral dimensions of their actions. Here I want to focus more on the long term implications of the villagization scheme. I do not want to get bogged down in the already over contested procedural issues, i.e. whether it was forced or voluntary, rather I take an analytical, not an exhaustive approach.

The villagization plans of the Ethiopian government have the intention of transforming local people into surplus producers. This intention is best captured by the term utilized by implementers of the scheme in reference to the now villages: "development centers". Shifting cultivators and (agro) pastoralists are not commercially oriented, and there socio-economic i.e. organization and resources use is geared toward risk aversion through expansive natural resources use. This has meant that these people groups never engaged in intensive and efficient natural resources usage in the past. The viability of the livelihood systems was considered only within each group, thus not contributing as much to the national economy as the vast lamp resources would allow.

\section{Trust Engineering in Ubiquitous Computing System}

Trust has been shown to be a key factor for technology adoption by users, i.e. users prefer to use applications they trust. Surprisingly, trust literature offers very little guidance for systematically integrating the vast amount of behavioural trust research results into the development of computing system. The talk presents a method for deriving trust supporting components for ubiquitous computing systems form empirical research models. Using the method we derive four trust supporting components, for a ubiquitous restatement recommendation system, the system is consequently evaluated with and without trust-supporting components using a laboratory experiment with 166 undergraduate students. The result shows that the users' trust as well as their intention to use the system could be significantly increased by the trust supporting components. To the best of our knowledge, this is the first approach developing and evaluating a method for systematically integrating the behavioural trust results into the development of a computing system and the potential value contribution of such an approach.

\section{User Engineering and the Theory of Experience}

The user engineering is an offspring of the usability engineering. The usability engineering, as the name reveals, (focuses on the usability that is quite important to users. But there are also such important quality traits as the reliability, the safety, thE compatibility etc. in addition to the usability. The user engineering treats all the quality characteristics that are relevant to the user of the purpose of increasing the level of satisfaction on the side of the user. Since around 2000 UX (user experience) become the major concern of designers, engineers and marketing people instead of the usability. But it should be noted that there was a shift and focus from the user side to the industry side despite the name of UX, in other words, UX is attracting stakeholders as an 
approach to increase the sales. This is the reason why I proposed the concept of experience engineering that also put an emphasis on the user side as the user engineering. There are three key aspect of artifacts as follows; objective quality characteristics, subjective quality characteristics and more importantly, the meaningfulness. The experience engineering denies products and services that are meaningless to users and proposes an approach to acquire the meaningfulness.

\section{Research: The Push to the Edges}

\section{New State of Play in Information System (IS)}

Dominant and preferred ways of producing knowledge underlying current information system (IS) scholarship are driven by the desire to domesticate higher level reference theory in the form of mid-level abstractions within a research context that involves information technology (IT). As IT remains exogenous to these theories it is typically treated as an independent variable, mediator or moderator, depending on the adopted research angle. The construct itself is operationalized through rough proxy measures that detect the presence of generic technical elements in a social context. This has resulted in a growing number of interpretations and operationalizations of reference theories and "IT" leaving "IS" scholars to grapple with incommensurate models and often confounding results, which are difficult to coalesce into a strong and cumulative knowledge-base.

At the same time the discourse communicates complains about the paucity of original and bold theorizing. As one way to overcome these challenges we suggest that is "IS" community news to reconsider and revise its epistomic scripts in ways that more flexibility accommodate new forms of producing knowledge. These scripts will start push "IS" inquiry to the edges by emphasizing inductive, rich and pre-science local theorizing based using new and extensive data, as well by pursuing genuine high level and stylized theorizing what focuses on interactions between "IT", information and semiotic representations and social behaviours. The push calls for relaxing and revising current institutionalized publishing and review practices reassessing our expectations concerning research genres deemed worthy of publishing. We posit that if proposed shifts to "edges" can be accomplished the future of "IS" discipline is brighter and it can establish itself as one of the epicenters of organization at inquiring into forces that shape human enterprise in the $21^{\text {st }}$ century.

\section{Performing Identity with Digital Material: A Socio-Material Perspective of Virtual Worlds}

In the contemporary era of social media and virtual organizing people increasingly materialize themselves by means of blogs, images, profiles and tweets. As they leverage digital material to make themselves personal in multiple settings, they increasingly become cyborg that is, being whose bodies and senses are extended through technology. They find themselves having to manage who they are in a luminal zone where the boundaries between actual and virtual reality and between their physical and digital identities are blurred. Even as users are increasingly experiencing their identities as socio-material entanglements, most research on online identity draw a priori distinctions between the "real" and the virtual and between the physical - embodied users and his or her technological representation. To address this short-coming, this paper adopts a performative perspective of identify in order to gain insight into the practices that users of virtual words, a particular kind of social media technology, rely on to perform a cyborgian identity. By focusing on the role of digital material in the performance of eight second life users, this study seeks tot answer the question: how is digital material available in virtual worlds used to perform cyborgian identity? The paper identifies some identity practices; the materialization of new discourses, embodiment and the materialization of identity positioning.

\section{Paradox in Technology Ecosystem Governance}

Technology platform strategies offer a novel way to orchestrate a rich portfolio of contributions made by many independent actions who form an ecosystem of heterogeneous compliments around a stable platform core. This form of organizing has been successfully used in the smart phone, gaining, social-networking, and commercial software industries, amongst others. Technology ecosystems require stability and homogeneity to leverage common investment in standard components, yet also need change and heterogeneity to meet evolving market demand.

We explore these issues through a case study of a business software ecosystem manufacturer at the core, and a system of independent implementation partners and solution developers on the periphery. Our research analysis three primary tensions control autonomy, standardization variety and collective individual. We explore the mechanisms of the ecosystem of governance that accommodate these tensions and highlight the specific properties that can be generalizable to other technology ecosystems. Finally we identity triggers in the case data were latent, mutually enabling tensions become manifest as salient, disabling tensions. By identifying transitions between the complementary and contradictory logics, our study contributes to the understanding of both the design of the ecosystem governance but also the constant managerial finesse needed to achieve equilibrium and avoid problems of "market failure" in technology ecosystems that function as semi-regulated market places. 


\section{Ambidextrous Socialization Exercising Control in Social Media Environment}

How can firm use social media environments, (SMES) to create productive ideas within an extended organization particularly if customers do not have strong identification with the company? How can firms control heterogeneous social media users, to achieve organizational goals? These questions are important as the prevailing literature on SME assume that firms can exert little control over individuals automatons behaviours, based on empirical observations on how one firm used SME to increase customer engagement and innovation, we argue that in collective, heterogeneous and rapidly changing knowledge intensive environments, co-creation in socialization of users is based on fundamentally different, logic than in traditional organizations. We advance the concept of ambidextrous socialization, that rather than reducing uncertainty those users feel in socialization, seek to increase uncertainty and thereby promote flexibility, plurality and adaptability in volatile, virtual and fast moving environments.

\section{Digital Infrastructure Evolution Generative Mechanism}

The literature on digital infrastructure offers powerful lenses for conceptualizing the increasingly interconnected information system collectives found in contemporary organization. However, little attention has been paid to the generative mechanisms of digital infrastructure that is the causal powers that explain how and why such infrastructure evolves over time. This is unfortunate, since more knowledge and what drives digital infrastructure would be highly valuable for managers among IT professionals confronted by the complexity of managing them. To this end, we adopt a critical realist view for developing a configurationally perspective of infrastructure evolution, our theorizing draws on a multi-method research design comprising an in-dept case study and a case survey research of 41 cases of digital infrastructure then identifies and analyzes causal paths through which configurations of these mechanisms lead to successful evolution outcomes. Our study contributes to the infrastructure literature in two ways. First we identify three generative mechanisms of digital infrastructure and how they contingently lead to evolution outcomes. Second, we use these mechanisms as a basis for developing a configurational perspective that advances current knowledge about why some digital infrastructures evolve successfully while others do not.

\section{Digital Innovation Challenges}

The technical process of digitizing analogue data into digital bit-streams and the associated sociotechnical process of digitalization has yet to fully reveal their disruptive potentials yet researchers and practitioners alike must comprehend these phenomena. The associated digital innovation brings a number of research themes to the foreground and the aim of this talk is to discuss a couple of these themes as a way of stimulating the debate on how research can provide useful insights. Special focus will be drawn to the relationship between ecosystem governance and innovation dynamism stemming form a large-scale study of apple's 10s ecosystem, the presentation draw upon current research on mobile platform innovation conducted at LSE's unit for the study of digital infrastructure innovation.

\section{Innovation Dynamics and the Installed Base}

Information system (IS) innovations often consist of piecemeal additions, improvements, recombination and reuse of previous elements. The interplay between the novel impulse (or element) and the existing reality (the installed base) results in complex innovation trajectories and in complex, heterogeneous and layered information system (IS) solutions. An adequate understanding of "IS" innovation dynamics requires that we are able to grap this complex interplay. The concept of installed base, coming from network economics initially denoted quantitative, measures such as market share. In the IS field it also denotes the socio-technical heterogeneity of the environment, such as existing organizations, routines, tools, systems, standards, practices, etc. while the concept helps us to address stability and continuity, the question remains whether (and how) it may offer analytic leverage beyond this far innovation studies. At the very least we need to push beyond the insight that the installed base is "both enabling and constraining" for innovation in order to external the conceptual granularity often installed base concept, empirical material from attempts in the healthcare sector to design patient. Centric services and ICTS will be presented. In these cases, the interplay between installed based and innovation process is differentiated along multiple dimensions, such as points of contact, modes of engagement and degrees of coupling.

\section{Honest Signals of Innovation}

Every disruptive innovation is not the result of a lone inventor, but of a small group of likeminded individuals, working together in close collaboration to get their cool idea off the ground. They are leveraging the concept swarm creativity, where this small teem - the collaborative innovation network (COIN) empowered by the collaborative technologies of the internet and social media, turn their creative labour of love into a product 
that changes how we think, work or spend our day. The seminar described a series of original projects at the MIT centre for collective intelligence with the goal of analyzing the new idea creation process through tracking human interaction patterns on three levels. On the global level, macro and microeconomic indicators such as the valuation of companies and consumers indices are predicted based on social media analysis on Twitter, Blogs and Wikipedia. On the organizational level, productivity and creativity of companies and teams is measured through extracting "honest signals" from communication archives such as company e-mail. On the individual level, individuals and team creativity is analyzed through face to face interaction with socio-metric badges and personal email blogs. After introducing the framework, the talk presented ongoing projects on all three levels.

\section{Improving Customers Information Technology Via E-Commerce}

Web-sites are a companies "window to the world". A Web site allows customers to interact directly with a number of information technology artifacts that are provided by the company (such as product recommendation agents, video product presentations) as well as entities with that company (such as sales assistants) and other customers (collaborative shopping) via information technology mediated channels. This interaction is designed to enhance customers efficiency, effectiveness and shopping environment by providing high quality information technology-based services with the aim of improving customers trust in online merchants, reducing their perceived risks of buying on the web and increasing their loyalty to web merchants and commitment to online shopping.

This paper provides a brief summary of students on electronic commerce using laboratory experimentation and field survey methods. The topics studied includes: how to improve product understanding on the web, how to provide services to customers via IT support; improving customers purchase quality via recommendation agent use designing product recommendations agents that are trustworthy, and designing social interfaces to such agents; collaborative shopping, and reducing risk and deception in electronic commerce.

\section{Paradigms for Understanding Digital Change in a Dynamic Messy World}

As Business environment become more dynamic and discontinuous, the phenomenon of digital transformation becomes more complex non-linear, and messy. When change in the context of the phenomenon that we study becomes profound, then it will result to our research paradigms for studying of digital transformation and digital business strategy in a dynamic messy world. I use three contextual examples which are in varying degrees of development to articulative research paradigms. The first instance demonstrates the use of configurational approaches for examining digital eco-dynamics and shows how configurational approaches to both theory structure and method yield different results and insights them do correlational approaches in studying how IT enhances or inhibits organizational, agility. The second instances searches for the building blocks of a suitable theory structure, and accompanying methods for capturing interactive senseand-respond phenomena associated with the management of the real time digital interprise in a big data world. The third instance examines evolving ideas on two-domain holomic models and how they might help to design architectures for the digital adaptive enterprise. The instances are in descending order with respect to their degree of development, and each will be explained through an appropriately different genre of presentation.

\section{Recommendations}

Most ICT are located in the urban areas, in the same manner the teaming targeted population have there roots in the urban areas. Holding to this, it is only logical for the urban people and the state government authorities to take the lead in this enterprise. Nevertheless, ICT resources should be packaged by the state ministry of information and communication. The idea of viewing ICT as a foreign taste should be discouraged. The intrinsic value of ICT is capable of diversifying Nigerian's mono-economy.

The role of government in the promoting of ICT as a change agent for socialization and social engineering could be direct or partial. In direct, the government takes the lead in providing ICT facilities and even funding installation centres such as ICT centres, schools, etc. Government should also provide the necessary social infrastructure that aids ICT installations, this would includes, improvement in the transportation, rail, air water security, etc.

\section{Conclusion}

ICT as a change agent for socialization and social engineering could only be realized if the government is fully involved in the race. For this to be feasible, it requires both private and public participation in the ICT world. In the era of intra-ethnic and inter-religious crises, ICT can be a unifying factor and also an agent of healing many sour wounds in the society.

\section{References}

[1]. Carsten, S. (2013) Digital innovation challenges, Struggling with Paradoxes of change and control: Department of IT Management, London School of Economics.

[2]. Fana, E. (2014) Social engineering or formal relocation in Ethiopians' low lands: A blog of African program at the Wilson Centre. 
[3]. Izak, B. (2013) Improving customers technology. Department of IT Management University of Columbia.

[4]. Jonathan, W. (2012) Paradox in technology ecosystem Governance. Department of IT Management ESADE.

[5]. Jan, M.L (2012) Trust Engineering in ubiquitous compacting system. Department of IT Management Kassel University.

[6]. Kalle, L. (2012) New Sate of Ply in 'IS' research; the push to the edges. Department of IT Management, Case Western Reserve University.

[7]. Khanna, U.K. (2003) Digital signal processing telecommunication and Multimedia Technology. New Delhi, S. Channel \& Co Ltd Ram Nagar New Delhi - 110055

[8]. Margunn, A. (2013) Innovation Dynamics and installed Base. Department of IT Management University of Oslo.

[9]. Massaaki, K. (2013) User engineering and theory experience. Department of IT Management, the Open University of Japan.

[10]. Ogbu, E.C. (2014) Reading in Sociology. Port Harcourt. Agipe Int'l Co RIVCAS Rumuola, Port Harcourt.

[11]. Ola, H. 92012) "The Generative Mechanism of digital infrastructure evolution. Department of IT Management, Warwick Business School.

[12]. Omar, A. \& E.L Sawy (2014) Rethinking research. Department of IT Management: University of Southern California.

[13]. Peter, G. (2013) Analyzing big data discover honest signals of innovation. Department of IT Management. Massachusetts Institute of Technology.

[14]. Virpi, T. (2013) Ambidextrous Socialization. Department of IT Management AALTO University.

[15]. West, G.T., (2003) Computer and Data Processing. Agipe Int'l Co RIVCAS Rumuola, Port Harcourt. 